\title{
Pre-diagnostic body mass index and weight change in relation to colorectal cancer survival among incident cases from a population-based cohort study
}

Ida Laake ${ }^{1,2^{*}}$, Inger K. Larsen ${ }^{3}$, Randi Selmer ${ }^{4}$, Inger Thune ${ }^{5,6}$ and Marit B. Veierød $d^{1,7}$

\begin{abstract}
Background: Whether excess body weight influences colorectal cancer (CRC) survival is unclear. We studied pre-diagnostic body mass index (BMI) and weight change in relation to CRC-specific mortality among incident CRC cases within a large, Norwegian cohort.

Methods: Participants' weight was measured at health examinations up to three times between 1974 and 1988. CRC cases were identified through linkage with the Norwegian Cancer Registry. In total, 1336 men and 1180 women with a weight measurement $>3$ years prior to diagnosis were included in analyses. Hazard ratios (HRs) and confidence intervals (Cls) were estimated with Cox regression.

Results: During a mean follow-up of 5.8 years, 507 men and 432 women died from CRC. Obesity (BMl $\left.\geq 30 \mathrm{~kg} / \mathrm{m}^{2}\right)$ was associated with higher CRC-specific mortality than normal weight (BMI $18.5-25 \mathrm{~kg} / \mathrm{m}^{2}$ ) in men with proximal colon cancer, $\mathrm{HR}=1.85$ (95\% Cl 1.08-3.16) and in women with rectal cancer, $\mathrm{HR}=1.93$ (95\% Cl 1.13-3.30). Weight gain was associated with higher CRC-specific mortality in women with CRC, colon cancer, and distal colon cancer, HRs per $5 \mathrm{~kg}$ weight gain were 1.18 (95\% Cl 1.01-1.37), 1.22 (95\% Cl 1.02-1.45), and 1.40 (95\% Cl 1.01-1.95), respectively. Weight gain was not significantly associated with survival in men.
\end{abstract}

Conclusions: Maintaining a healthy weight may benefit CRC survival, at least in women.

Keywords: Colorectal cancer, Survival, Body mass index, Weight change, Cohort study

\section{Background}

Excess body weight is an established risk factor for colorectal cancer (CRC) in both men and women, and a positive association between body mass index (BMI) and CRC incidence has been found in numerous studies [1]. The association is stronger in men than in women and stronger for colon than for rectal cancers [1]. Furthermore, the association seems to be stronger for distal than for proximal colon cancers [2]. These observations support that the biological mechanisms operating may vary by sex and colorectal subsite.

\footnotetext{
* Correspondence: ida.laake@fhi.no

${ }^{1}$ Oslo Centre for Biostatistics and Epidemiology, Institute of Basic Medical Sciences, University of Oslo, Oslo, Norway

2Department of Vaccines, Norwegian Institute of Public Health, Oslo, Norway Full list of author information is available at the end of the article
}

Less is known about the influence of excess body weight on CRC survival. However, it is possible that the mechanisms linking excess body weight to development of CRC tumors, related to e.g. insulin, insulin-like growth factors, inflammation, and steroid hormones, also influence tumor progression and thereby survival of the disease $[3,4]$. Some studies have evaluated the association between BMI at the time of treatment, i.e. around the time of diagnosis, and survival after colon $[5-7]$ or rectal cancer $[8,9]$, but the results are difficult to interpret since weight loss is a clinical feature of CRC [10]. Thus, the patients' weight might be a consequence of the disease itself ('reverse causation'). Moreover, whether maintaining a healthy weight throughout adulthood is important not only for CRC prevention, but also for CRC survival, is not clear from these studies. Pre- 
diagnostic BMI is probably a better marker of weight across life-course than BMI at the time of diagnosis.

A recent meta-analysis found that pre-diagnostic obesity (BMI $\geq 30 \mathrm{~kg} / \mathrm{m}^{2}$ ) was significantly associated with poorer survival after CRC [11]. However, this metaanalysis only presented results for men and women combined and for CRC overall. Few of the studies that have evaluated the association between pre-diagnostic BMI and CRC survival have examined whether results differ for men and women [12-17] or between CRC subsites [12-14, 17-21]. Finally, although adult weight gain is related to increased colon cancer risk [22], only one study has examined pre-diagnostic weight change and survival after CRC [17].

We have previously studied BMI and weight change in relation to colon cancer risk in the Norwegian Counties Study [23]. The aim of the present study was to examine sex-specific and subsite-specific associations between BMI and weight change measured prior to diagnosis and survival among incident CRC cases from this cohort.

\section{Methods}

\section{The Norwegian counties study}

The Norwegian Counties Study is a population-based Norwegian cohort study described in detail elsewhere $[23,24]$. In short, participants were examined by a team of trained nurses at health screenings up to three times between 1974 and 1988. The attendance rate was $>80 \%$ at all three screenings, and 92,234 men and women attended at least one screening. At each screening, the participants' height was measured to the nearest centimeter and weight to the nearest 0.5 kilo. Information on lifestyle factors such as smoking habits and recreational and occupational physical activity during the last year was collected with a questionnaire.

Using the unique personal identification number assigned to all Norwegian citizens, information on each participant's education was obtained from records of the censuses in 1970, 1980, 1990, and 2001. The most recent information available was used.

\section{Case identification}

CRC cases were identified through linkage with the Cancer Registry of Norway, i.e. cancers coded as 153 or 154 according to the International Classification of Diseases, Seventh edition (ICD-7). The cases were categorized as colon cancer (ICD-7: 153) or rectal cancer (ICD-7: 154). Furthermore, cancers of the appendix, cecum, ascending or transverse colon (including the hepatic and splenic flexures) (153.0, 153.1, and 153.6) were categorized as proximal colon cancer. Cancers that occurred in the descending colon, sigmoid colon, or rectosigmoid junction (153.2 - 153.4) were categorized as distal colon cancer.
We only considered the first cancer diagnosis. Participants diagnosed with multiple malignant tumors at the date of first diagnosis were included as CRC cases if all the cancers occurred in the colorectum. Correspondingly, multiple cancers were included as a cancer of one of the subsites (colon, proximal colon, distal colon, or rectum) if they all occurred in the same subsite. The cases were classified according to stage at diagnosis as localized, regional, or distant. For participants with multiple malignant tumors, stage at diagnosis was defined as the stage of the most advanced.

We identified 2786 cases of CRC among the cohort participants. Of these, 69 were diagnosed with multiple malignant tumors.

\section{Study sample}

For each case, we obtained information on weight, smoking, and physical activity level from the most recent screening. This screening was defined as the case's exposure screening if 1) no information was missing and 2) the screening took place at least 3 years prior to diagnosis. Otherwise, the most recent preceding screening fulfilling these requirements was defined as the exposure screening. Pre-diagnostic BMI $\left(\mathrm{kg} / \mathrm{m}^{2}\right)$ was calculated as weight at the exposure screening divided by height squared, using the mean height from all attended screenings. We excluded 54 cases with missing information on weight, smoking, and physical activity at all three screenings, 35 cases diagnosed before information was collected, and 44 cases diagnosed $<3$ years after the information was collected. We furthermore excluded 5 cases with no height measurements and 6 cases without information on education. We also excluded 23 cases with $\mathrm{BMI}<18.5 \mathrm{~kg} / \mathrm{m}^{2}$ at the exposure screening due to concerns that their weight was influenced by preexisting CRC or other underlying health problems that may influence survival. Finally, we excluded 97 cases with unknown stage at diagnosis, 2 cases with date of diagnosis equal to date of death, and 4 cases with date of emigration prior to their date of diagnosis.

In total, 2516 CRC cases, 1336 men and 1180 women, diagnosed between 1978 and 2012, were included in analyses of BMI and CRC survival (Additional file 1 : Figure S1). In men, 847 of the cases were colon cancers, of which 443 occurred in the proximal and 369 in the distal colon, and 478 cases were rectal cancers. In women, 808 cases were colon cancers, 493 were proximal colon cancers, 294 were distal colon cancers, and 367 were rectal cancers.

For analyses of weight change, we furthermore excluded 622 cases with no weight measurements prior to the exposure screening, leaving 999 men (637 colon cancers, 339 proximal colon cancers, 270 distal colon cancers, 351 rectal cancers) and 895 women (608 colon 
cancers, 383 proximal colon cancers, 207 distal colon cancers, 283 rectal cancers) (Additional file 2: Figure S2).

We determined the power of detecting an effect estimate per 5 unit increase in BMI of 1.20 with a significance level of 0.05 in our study sample [25]. We used the standard deviation of BMI among CRC cases, $3.2 \mathrm{~kg} /$ $\mathrm{m}^{2}$ in men and $4.5 \mathrm{~kg} / \mathrm{m}^{2}$ in women. In men, the power was 0.87 for CRC, 0.69 for colon cancer, 0.41 for proximal colon cancer, 0.31 for distal colon cancer, and 0.46 for rectal cancer. In women, the power was $0.97,0.87$, $0.68,0.45$, and 0.60 for CRC, colon cancer, proximal colon cancer, distal colon cancer, and rectal cancer, respectively.

The cases were followed from the date of diagnosis until death, emigration, or December 31, 2012. Information on death and emigration was obtained from the Cause of Death Registry and the National Population Registry. CRC-related death was the primary outcome and death from all causes was the secondary outcome. Deaths with cause 153-154 (ICD-8 and ICD-9) or C18-21 (ICD-10) were considered CRC-related deaths.

\section{Statistical analysis}

Pre-diagnostic BMI was categorized according to WHO guidelines: $18.5-24.9 \mathrm{~kg} / \mathrm{m}^{2}$ (normal weight), $25-29.9 \mathrm{~kg} / \mathrm{m}^{2}$ (overweight), and $\geq 30 \mathrm{~kg} / \mathrm{m}^{2}$ (obese) [26]. Weight change was defined as weight at the exposure screening minus initial weight, i.e., weight at the first attended screening, and was categorized as $\leq-2.0 \mathrm{~kg}$ (weight loss), $-1.9-1.9 \mathrm{~kg}$ (weight maintenance), $2.0-7.9 \mathrm{~kg}$ (moderate weight gain), and $\geq 8.0 \mathrm{~kg}$ (large weight gain).

We examined BMI and weight change in relation to risk of death from CRC, our primary outcome, and risk of death from all causes. Hazard ratios (HRs) and $95 \%$ confidence intervals (CIs) were estimated with Cox regression. We used a stratified Cox model with stage of disease at diagnosis as the strata (localized, regional, or distant) and time since diagnosis as the time variable. We adjusted for smoking (never, former, current) and level of recreational and occupational physical activity combined (sedentary, moderately active, or active) [23], both measured at the exposure screening, education (primary schooling ( $\leq 9$ years), secondary education (1012 years), or university level education ( $\geq 13$ years)), age at diagnosis (continuous) and year of diagnosis $(<1990$, 1990-94, 1995-99, 2000-2004, and $\geq 2005$ ). Analyses of weight change were also adjusted for initial BMI (continuous). Adjustment for time between the exposure screening and diagnosis did not change the results and was not included in the model. To test for trend, BMI/ weight change was modeled continuously and evaluated with a Wald test. All analyses with continuous weight change were restricted to subjects who maintained or gained weight because we hypothesized that weight loss may cause a $\mathrm{J}$ or U-shaped relation. We furthermore tested whether the associations with CRC-specific mortality differed in the colon and rectum or in the proximal and distal colon by testing the difference in trends with a Wald statistic. To assess whether associations differed with sex, we included interaction terms between sex and BMI (continuous) or between sex and weight gain (continuous). For CRC, we also examined whether the association between weight gain (continuous) and mortality differed with initial BMI $\left(<25 \mathrm{~kg} / \mathrm{m}^{2}\right.$ and $\left.\geq 25 \mathrm{~kg} / \mathrm{m}^{2}\right)$. Tests of interaction were evaluated with a likelihood ratio test and were done for CRC-specific mortality only. Proportional hazards assumptions were evaluated with a test based on the Schoenfeld residuals. The tests did not indicate violations of the assumption. All tests were two sided, and $P<0.05$ was considered statistically significant. The analyses were performed with SAS version 9.4 (SAS Institute, Cary, NC).

\section{Results \\ Body mass index}

Mean age at diagnosis in the BMI study sample $(n=$ 2516) was 66.4 years (range 32.0-85.6) in men and 66.8 years (range 36.0-86.4) in women. During a mean follow-up of 5.8 years, 703 men and 543 women died. Of these, 507 men and 432 women died from CRC. Time from BMI measurement to diagnosis ranged from 3.0 to 37.5 years (mean 17.8 years). Mean pre-diagnostic BMI was similar in men and women, $26.0 \mathrm{~kg} / \mathrm{m}^{2}$ and $25.7 \mathrm{~kg} / \mathrm{m}^{2}$, respectively. For both men and women, the proportion with a university education was highest among those with normal weight (Table 1). With increasing BMI, the proportion of sedentary subjects increased, the proportion of current smokers decreased, and mean systolic blood pressure increased. Furthermore, age at diagnosis increased and the proportion with distant stage disease decreased with increasing BMI in women.

In men with proximal colon cancer, pre-diagnostic obesity was associated with higher risk of CRC-related death than normal weight, HR $=1.85$ (95 \% CI 1.083.16) (Table 2). BMI was not significantly associated with CRC-specific mortality in men with $\mathrm{CRC}$, colon cancer, distal colon cancer, or rectal cancer. In women, we found no significant associations between BMI and risk of CRC-related death after diagnosis of CRC or cancer of any colon subsite. However, obese women had significantly increased risk of CRC-related death after diagnosis of rectal cancer, HR $=1.93$ (95\% CI 1.13-3.30). We found no significant interactions between BMI and sex $\left(P_{\text {interaction }} \geq 0.26\right)$. The associations between BMI and 
Table 1 Characteristics of CRC cases by pre-diagnostic BMI, $n=2516$

\begin{tabular}{|c|c|c|c|c|c|c|}
\hline & \multicolumn{3}{|l|}{ MEN } & \multicolumn{3}{|l|}{ WOMEN } \\
\hline & \multicolumn{3}{|c|}{ BMI $\left(\mathrm{kg} / \mathrm{m}^{2}\right)$} & \multicolumn{3}{|c|}{ BMI $\left(\mathrm{kg} / \mathrm{m}^{2}\right)$} \\
\hline & $18.5-24.9$ & $25-29.9$ & $\geq 30$ & $18.5-24.9$ & $25-29.9$ & $\geq 30$ \\
\hline Number of cases & 544 & 662 & 130 & 626 & 366 & 188 \\
\hline Follow-up (years), mean & 6.1 & 5.4 & 5.5 & 6.1 & 5.9 & 5.7 \\
\hline University level education (\%) & 13.8 & 12.7 & 8.5 & 12.0 & 6.8 & 7.4 \\
\hline Current smokers (\%) & 51.1 & 38.5 & 35.4 & 46.0 & 32.5 & 22.9 \\
\hline Sedentary (\%) ${ }^{a}$ & 26.5 & 26.9 & 36.2 & 27.5 & 32.0 & 35.6 \\
\hline Systolic blood pressure $(\mathrm{mmHg})^{\mathrm{a}}$, mean & 134 & 138 & 145 & 128 & 137 & 145 \\
\hline \multicolumn{7}{|l|}{ Exposure screening (\%) } \\
\hline Screening 1 & 7.2 & 7.4 & 1.5 & 9.6 & 3.3 & 8.0 \\
\hline Screening 2 & 29.6 & 26.9 & 30.0 & 29.9 & 27.9 & 22.9 \\
\hline Screening 3 & 63.2 & 65.7 & 68.5 & 60.5 & 68.9 & 69.1 \\
\hline Age at exposure screening (years), mean & 47.9 & 49.1 & 49.5 & 47.8 & 50.3 & 50.7 \\
\hline $\begin{array}{l}\text { Time between exposure screening and } \\
\text { diagnosis (years), mean }\end{array}$ & 17.7 & 18.2 & 15.6 & 18.1 & 17.5 & 17.6 \\
\hline Age at diagnosis (years), mean & 65.6 & 67.3 & 65.1 & 65.8 & 67.9 & 68.2 \\
\hline \multicolumn{7}{|l|}{ Stage at diagnosis (\%) } \\
\hline Localized & 24.3 & 24.6 & 22.3 & 27.0 & 25.7 & 26.6 \\
\hline Regional & 52.4 & 48.5 & 52.3 & 46.3 & 50.5 & 53.7 \\
\hline Distant & 23.3 & 26.9 & 25.4 & 26.7 & 23.8 & 19.7 \\
\hline
\end{tabular}

${ }^{a}$ At exposure screening

risk of CRC-related death did not differ significantly with subsite: colon vs. rectum $\left(P_{\text {heterogeneity }} \geq 0.27\right)$, proximal vs. distal colon $\left(P_{\text {heterogeneity }} \geq 0.33\right)$. In contrast with the results on CRC-related death, pre-diagnostic obesity was associated with higher all-cause mortality in men with CRC and colon cancer (Additional file 3: Table S1). In women, associations between pre-diagnostic BMI and all-cause mortality were similar to the associations found for $\mathrm{CRC}$-specific mortality.

\section{Weight change}

In the weight change study sample $(n=1894), 533$ men and 414 women died during follow-up. Of these, 372 men and 326 women died from CRC. Mean weight change was $2.5 \mathrm{~kg}$ in men and $2.0 \mathrm{~kg}$ in women. Cases who lost weight prior to diagnosis had a higher initial BMI and were more likely to be current smokers than cases who maintained or gained weight (Table 3). Furthermore, the highest proportion of sedentary subjects was found among those who gained $\geq 8 \mathrm{~kg}$. In men, the proportion with distant stage disease was lowest among those who had maintained their weight and the proportion increased with increasing weight gain, whereas in women the proportion with distant stage disease decreased with increasing weight gain.

Pre-diagnostic weight gain was not significantly related to CRC-specific mortality in men, but weight loss was associated with significantly increased risk of CRCrelated death compared to weight maintenance in men with rectal cancer, $\mathrm{HR}=1.78$ (95 \% CI $1.06-3.00)$ (Table 4). In women, weight gain was significantly associated with increased risk of death from CRC after diagnosis of CRC, $\mathrm{HR}=1.18$ (95\% CI 1.01-1.37) per $5 \mathrm{~kg}$ weight gain, $\mathrm{P}_{\text {trend }}=0.03$. Moreover, in women with colon cancer, moderate and large weight gain were both associated with significantly increased risk of CRC-related death compared to weight maintenance, HRs $=1.54(95 \% \mathrm{CI}$ $1.08-2.20)$ and 1.64 (95\% CI 1.03-2.63), respectively, $\mathrm{P}_{\text {trend }}=0.03$. For proximal colon cancer, we observed increased risk in women with moderate weight gain, $\mathrm{HR}=1.59$ (95\% CI 1.01-2.49), but not in women with large weight gain. In women with distal colon cancer, large weight gain was associated with significant, increased risk of CRC-related death compared to weight maintenance, $\mathrm{HR}=2.99$ (95 \% CI 1.27-7.05), $\mathrm{P}_{\text {trend }}=0.04$. Weight change was not associated with CRC-specific mortality in women with rectal cancer. No significant interactions between weight gain and sex were observed $\left(P_{\text {interaction }} \geq 0.18\right)$. The associations did not differ significantly with subsite; colon vs. rectum $\left(\mathrm{P}_{\text {heterogeneity }} \geq 0.38\right)$, proximal vs. distal colon ( $P_{\text {heterogeneity }} \geq 0.12$ ). We did not observe significant interactions between $\mathrm{BMI}$ and weight gain $\left(P_{\text {interaction }} \geq 0.33\right)$. The results on all-cause mortality were similar to the results on CRC-specific mortality, 
Table 2 Hazard ratios and $95 \%$ confidence intervals for CRC-specific mortality by pre-diagnostic BMI

\begin{tabular}{|c|c|c|c|c|c|}
\hline & \multicolumn{4}{|c|}{ BMI $\left(\mathrm{kg} / \mathrm{m}^{2}\right)$} & \multirow[b]{2}{*}{$P_{\text {trend }}{ }^{a}$} \\
\hline & $18.5-24.9$ & $25-29.9$ & $\geq 30$ & Per $5 \mathrm{~kg} / \mathrm{m}^{2}$ & \\
\hline \multicolumn{6}{|l|}{ MEN } \\
\hline \multicolumn{6}{|l|}{ CRC, $n=1336$} \\
\hline Person-years & 3320 & 3563 & 710 & & \\
\hline Number of CRC-related deaths & 198 & 254 & 55 & & \\
\hline $\mathrm{HR}(95 \% \mathrm{Cl})^{\mathrm{b}}$ & 1 (Ref) & $0.98(0.81,1.18)$ & $1.01(0.74,1.37)$ & $0.99(0.86,1.14)$ & 0.87 \\
\hline \multicolumn{6}{|l|}{ Colon cancer, $n=847$} \\
\hline Person-years & 1936 & 2144 & 433 & & \\
\hline Number of CRC-related deaths & 125 & 158 & 39 & & \\
\hline $\mathrm{HR}(95 \% \mathrm{Cl})^{\mathrm{b}}$ & 1 (Ref) & $1.02(0.80,1.30)$ & $1.26(0.87,1.83)$ & $1.07(0.90,1.28)$ & 0.43 \\
\hline \multicolumn{6}{|l|}{ Proximal colon cancer, $n=443$} \\
\hline Person-years & 1072 & 1058 & 160 & & \\
\hline Number of CRC-related deaths & 63 & 80 & 19 & & \\
\hline $\mathrm{HR}(95 \% \mathrm{Cl})^{\mathrm{b}}$ & 1 (Ref) & $1.17(0.82,1.66)$ & $1.85(1.08,3.16)$ & $1.19(0.93,1.54)$ & 0.17 \\
\hline \multicolumn{6}{|l|}{ Distal colon cancer, $n=369$} \\
\hline Person-years & 848 & 996 & 272 & & \\
\hline Number of CRC-related deaths & 53 & 65 & 18 & & \\
\hline HR $(95 \% \mathrm{Cl})^{\mathrm{b}}$ & 1 (Ref) & $0.91(0.63,1.33)$ & $0.91(0.52,1.59)$ & $0.98(0.75,1.30)$ & 0.91 \\
\hline \multicolumn{6}{|l|}{ Rectal cancer, $n=478$} \\
\hline Person-years & 1374 & 1371 & 273 & & \\
\hline Number of CRC-related deaths & 73 & 94 & 16 & & \\
\hline $\mathrm{HR}(95 \% \mathrm{Cl})^{\mathrm{b}}$ & 1 (Ref) & $0.99(0.71,1.37)$ & $0.75(0.43,1.33)$ & $0.93(0.73,1.17)$ & 0.52 \\
\hline \multicolumn{6}{|l|}{ WOMEN } \\
\hline \multicolumn{6}{|l|}{ CRC, $n=1180$} \\
\hline Person-years & 3793 & 2175 & 1064 & & \\
\hline Number of CRC-related deaths & 220 & 138 & 74 & & \\
\hline $\mathrm{HR}(95 \% \mathrm{Cl})^{\mathrm{b}}$ & 1 (Ref) & $1.07(0.85,1.33)$ & $1.31(0.99,1.72)$ & $1.04(0.93,1.17)$ & 0.51 \\
\hline \multicolumn{6}{|l|}{ Colon cancer, $n=808$} \\
\hline Person-years & 2469 & 1386 & 760 & & \\
\hline Number of CRC-related deaths & 153 & 90 & 50 & & \\
\hline $\mathrm{HR}(95 \% \mathrm{Cl})^{\mathrm{b}}$ & 1 (Ref) & $0.97(0.74,1.27)$ & $1.25(0.89,1.74)$ & $1.02(0.89,1.18)$ & 0.75 \\
\hline \multicolumn{6}{|l|}{ Proximal colon cancer, $n=493$} \\
\hline Person-years & 1279 & 876 & 372 & & \\
\hline Number of CRC-related deaths & 93 & 53 & 29 & & \\
\hline $\mathrm{HR}(95 \% \mathrm{Cl})^{\mathrm{b}}$ & 1 (Ref) & $0.89(0.63,1.28)$ & $1.23(0.80,1.91)$ & $1.02(0.84,1.24)$ & 0.82 \\
\hline \multicolumn{6}{|l|}{ Distal colon cancer, $n=294$} \\
\hline Person-years & 1160 & 467 & 369 & & \\
\hline Number of CRC-related deaths & 54 & 34 & 17 & & \\
\hline $\mathrm{HR}(95 \% \mathrm{Cl})^{\mathrm{b}}$ & 1 (Ref) & $1.33(0.84,2.11)$ & $1.18(0.64,2.16)$ & $1.06(0.83,1.35)$ & 0.65 \\
\hline \multicolumn{6}{|l|}{ Rectal cancer, $n=367$} \\
\hline Person-years & 1271 & 788 & 283 & & \\
\hline Number of CRC-related deaths & 67 & 47 & 24 & & \\
\hline $\mathrm{HR}(95 \% \mathrm{Cl})^{\mathrm{b}}$ & 1 (Ref) & $1.42(0.95,2.13)$ & $1.93(1.13,3.30)$ & $1.18(0.96,1.47)$ & 0.12 \\
\hline
\end{tabular}

\footnotetext{
Wald P-value for BMI as continuous variable

b Stratified Cox model (year of diagnosis: < 1990, 1990-1994, 1995-1999, 2000-2004, $\geq 2005$ ). Adjustment for age at diagnosis, stage of disease at diagnosis (localized, regional, or distant), smoking (never, former, or current), physical activity level (sedentary, moderately active, or active), education ( $\leq 9,10-12$, or $\geq 13$ years)
} 
Table 3 Characteristics of CRC cases by pre-diagnostic weight change, $n=1894$

\begin{tabular}{|c|c|c|c|c|c|c|c|c|}
\hline & \multirow{2}{*}{\multicolumn{4}{|c|}{$\begin{array}{l}\text { MEN } \\
\text { Weight change (kg) }\end{array}$}} & \multirow{2}{*}{\multicolumn{4}{|c|}{$\begin{array}{l}\text { WOMEN } \\
\text { Weight change }(\mathrm{kg})\end{array}$}} \\
\hline & & & & & & & & \\
\hline & $\leq-2$ & $-1.9-1.9$ & $2.0-7.9$ & $\geq 8.0$ & $\leq-2$ & $-1.9-1.9$ & $2.0-7.9$ & $\geq 8.0$ \\
\hline Number of cases & 155 & 295 & 418 & 131 & 194 & 256 & 323 & 122 \\
\hline Follow-up (years), mean & 5.4 & 6.3 & 5.4 & 5.3 & 5.4 & 6.1 & 6.3 & 5.3 \\
\hline Initial BMI $\left(\mathrm{kg} / \mathrm{m}^{2}\right)$, mean & 26.5 & 25.1 & 24.8 & 25.8 & 27.3 & 24.5 & 24.3 & 25.3 \\
\hline University level education (\%) & 7.1 & 9.2 & 12.0 & 8.4 & 5.2 & 7.4 & 10.5 & 10.7 \\
\hline Current smokers (\%) ${ }^{a}$ & 61.9 & 47.8 & 34.0 & 25.2 & 46.9 & 39.5 & 33.1 & 34.4 \\
\hline Sedentary $(\%)^{a}$ & 20.0 & 20.7 & 26.6 & 39.7 & 31.4 & 21.9 & 28.5 & 37.7 \\
\hline Systolic blood pressure $(\mathrm{mmHg})^{a}$, mean & 137 & 137 & 138 & 143 & 133 & 134 & 134 & 141 \\
\hline \multicolumn{9}{|l|}{ Exposure screening (\%) } \\
\hline Screening 2 & 31.6 & 42.7 & 31.3 & 14.5 & 39.2 & 44.5 & 30.7 & 8.2 \\
\hline Screening 3 & 68.4 & 57.3 & 68.7 & 85.5 & 60.8 & 55.5 & 69.3 & 91.8 \\
\hline Age at exposure screening (years), mean & 50.7 & 50.8 & 50.2 & 50.7 & 51.3 & 50.5 & 51.2 & 50.8 \\
\hline $\begin{array}{l}\text { Time between exposure screening and } \\
\text { diagnosis (years), mean }\end{array}$ & 16.8 & 17.2 & 18.0 & 16.7 & 18.3 & 18.1 & 17.4 & 16.5 \\
\hline Age at diagnosis (years), mean & 67.5 & 67.9 & 68.2 & 67.4 & 69.6 & 68.5 & 68.5 & 67.3 \\
\hline \multicolumn{9}{|l|}{ Stage at diagnosis (\%) } \\
\hline Localized & 27.1 & 26.8 & 23.9 & 21.4 & 27.3 & 27.0 & 28.2 & 27.9 \\
\hline Regional & 45.8 & 51.2 & 52.2 & 51.9 & 45.4 & 48.4 & 48.6 & 50.8 \\
\hline Distant & 27.1 & 22.0 & 23.9 & 26.7 & 27.3 & 24.6 & 23.2 & 21.3 \\
\hline
\end{tabular}

${ }^{\mathrm{a}}$ At exposure screening

except that weight gain was not significantly associated with higher all-cause mortality in women with CRC overall (Additional file 4: Table S2).

\section{Discussion}

In this study, obesity prior to diagnosis was significantly associated with higher CRC-specific mortality in men with proximal cancer and in women with rectal cancer. Furthermore, pre-diagnostic weight gain was significantly associated with higher CRC-specific mortality in women with CRC, colon cancer, proximal colon cancer, or distal colon cancer. Weight gain was not related to CRC-specific mortality in men. However, men with rectal cancer who had lost weight prior to diagnosis had increased risk of CRC-related death.

The association between BMI and CRC risk is stronger in men than in women [1], but whether there are sex differences regarding excess body weight and survival after CRC is not known. Our results did not indicate a stronger association in men. Results from previous studies are inconsistent. Men who were obese prior to diagnosis of CRC have been found to have poorer survival [14], while other studies have found weak or no associations [13, 15, 16, 27]. Likewise, both significantly poorer survival $[12,17,19]$ and no associations $[14,16,28]$ have been found in women who were obese prior to CRC diagnosis. Differences between the cases in these studies in terms of e.g. age at diagnosis, stage of disease, treatment, and subsite distribution may explain the disparities in the results. Another possible explanation is differences in the timing of BMI measurement in relation to diagnosis which may also influence the results.

We expected to find stronger associations between BMI and survival for colon cancer than for rectal cancer. However, in women, the opposite was observed. Results from previous studies are inconsistent. Pre-diagnostic obesity has been found to be associated with significantly poorer survival after both colon [14, 17, 19-21] and rectal cancer [12-14, 17], but no association with survival after colon cancer [13, 29] or after rectal cancer $[19,21]$ has also been reported. Only two studies have presented results on pre-diagnostic BMI in relation to survival after cancer in subsites of the colon $[14,18]$. These studies found that BMI was significantly associated with poorer survival after distal colon cancer, whereas a non-significant association was found for proximal colon cancer [14, 18]. Subsite-differences in the association between BMI and survival after diagnosis of CRC may be related to molecular features of CRC tumors. Microsatellite instable tumors tend to be proximal and are associated with better survival than microsatellite stable tumors [30]. Moreover, BMI has been found to be associated with an increased risk of 
Table 4 Hazard ratios and $95 \%$ confidence intervals for CRC-specific mortality by pre-diagnostic weight change

\begin{tabular}{|c|c|c|c|c|c|c|}
\hline & \multicolumn{5}{|c|}{ Weight change $(\mathrm{kg})$} & \multirow[b]{2}{*}{$P_{\text {trend }}$} \\
\hline & $\leq-2$ & $-1.9-1.9$ & $2.0-7.9$ & $\geq 8.0$ & Per $5 \mathrm{~kg}^{\mathrm{a}}$ & \\
\hline \multicolumn{7}{|l|}{ MEN } \\
\hline \multicolumn{7}{|l|}{$C R C, n=999$} \\
\hline Person-years & 836 & 1844 & 2240 & 694 & & \\
\hline Number of CRC-related deaths & 67 & 109 & 144 & 52 & & \\
\hline $\mathrm{HR}(95 \% \mathrm{Cl})^{\mathrm{c}}$ & $1.27(0.93,1.74)$ & 1 (Ref) & $0.95(0.73,1.23)$ & $0.93(0.65,1.32)$ & $1.01(0.87,1.19)$ & 0.86 \\
\hline \multicolumn{7}{|l|}{ Colon cancer, $n=637$} \\
\hline Person-years & 505 & 1043 & 1454 & 360 & & \\
\hline Number of CRC-related deaths & 38 & 70 & 92 & 35 & & \\
\hline $\mathrm{HR}(95 \% \mathrm{Cl})^{\mathrm{c}}$ & $0.96(0.64,1.44)$ & 1 (Ref) & $0.81(0.59,1.13)$ & $1.02(0.66,1.58)$ & $1.05(0.86,1.28)$ & 0.62 \\
\hline \multicolumn{7}{|l|}{ Proximal colon cancer, $n=339$} \\
\hline Person-years & 304 & 438 & 833 & 120 & & \\
\hline Number of CRC-related deaths & 14 & 38 & 52 & 19 & & \\
\hline $\mathrm{HR}(95 \% \mathrm{Cl})^{\mathrm{c}}$ & $0.59(0.31,1.12)$ & 1 (Ref) & $0.66(0.42,1.05)$ & $0.77(0.40,1.48)$ & $0.88(0.63,1.23)$ & 0.46 \\
\hline \multicolumn{7}{|l|}{ Distal colon cancer, $n=270$} \\
\hline Person-years & 195 & 576 & 575 & 224 & & \\
\hline Number of CRC-related deaths & 19 & 28 & 33 & 14 & & \\
\hline $\mathrm{HR}(95 \% \mathrm{Cl})^{\mathrm{c}}$ & $1.53(0.80,2.93)$ & 1 (Ref) & $0.95(0.55,1.62)$ & $1.50(0.75,3.00)$ & $1.25(0.94,1.66)$ & 0.13 \\
\hline \multicolumn{7}{|l|}{ Rectal cancer, $n=351$} \\
\hline Person-years & 330 & 798 & 737 & 325 & & \\
\hline Number of CRC-related deaths & 28 & 39 & 51 & 17 & & \\
\hline $\mathrm{HR}(95 \% \mathrm{Cl})^{\mathrm{C}}$ & $1.78(1.06,3.00)$ & 1 (Ref) & $1.21(0.78,1.87)$ & $0.76(0.40,1.44)$ & $0.95(0.74,1.23)$ & 0.70 \\
\hline \multicolumn{7}{|l|}{ WOMEN } \\
\hline \multicolumn{7}{|l|}{ CRC, $n=895$} \\
\hline Person-years & 1049 & 1562 & 2034 & 646 & & \\
\hline Number of CRC-related deaths & 72 & 91 & 119 & 44 & & \\
\hline $\mathrm{HR}(95 \% \mathrm{Cl})^{\mathrm{c}}$ & $1.14(0.82,1.59)$ & 1 (Ref) & $1.33(1.01,1.76)$ & $1.41(0.97,2.05)$ & $1.18(1.01,1.37)$ & 0.03 \\
\hline \multicolumn{7}{|l|}{ Colon cancer, $n=608$} \\
\hline Person-years & 670 & 1124 & 1270 & 473 & & \\
\hline Number of CRC-related deaths & 49 & 53 & 85 & 30 & & \\
\hline $\mathrm{HR}(95 \% \mathrm{Cl})^{\mathrm{c}}$ & $1.34(0.88,2.02)$ & 1 (Ref) & $1.54(1.08,2.20)$ & $1.64(1.03,2.63)$ & $1.22(1.02,1.45)$ & 0.03 \\
\hline \multicolumn{7}{|l|}{ Proximal colon cancer, $n=383$} \\
\hline Person-years & 423 & 673 & 645 & 247 & & \\
\hline Number of CRC-related deaths & 32 & 33 & 50 & 18 & & \\
\hline $\mathrm{HR}(95 \% \mathrm{Cl})^{\mathrm{c}}$ & $1.28(0.76,2.16)$ & 1 (Ref) & $1.59(1.01,2.49)$ & $1.49(0.81,2.75)$ & $1.18(0.95,1.47)$ & 0.14 \\
\hline \multicolumn{7}{|l|}{ Distal colon cancer, $n=207$} \\
\hline Person-years & 231 & 449 & 579 & 197 & & \\
\hline Number of CRC-related deaths & 15 & 18 & 29 & 12 & & \\
\hline $\mathrm{HR}(95 \% \mathrm{Cl})^{\mathrm{c}}$ & $1.52(0.71,3.25)$ & 1 (Ref) & $1.34(0.69,2.60)$ & $2.99(1.27,7.05)$ & $1.40(1.01,1.95)$ & 0.04 \\
\hline \multicolumn{7}{|l|}{ Rectal cancer, $n=283$} \\
\hline Person-years & 379 & 438 & 721 & 173 & & \\
\hline Number of CRC-related deaths & 23 & 37 & 34 & 14 & & \\
\hline $\mathrm{HR}(95 \% \mathrm{Cl})^{\mathrm{c}}$ & $0.93(0.52,1.64)$ & 1 (Ref) & $1.00(0.60,1.69)$ & $1.29(0.67,2.49)$ & $1.12(0.82,1.53)$ & 0.49 \\
\hline
\end{tabular}

\footnotetext{
analyses restricted to cases who maintained or gained weight

${ }^{\mathrm{b}}$ Wald P-value for weight gain as continuous variable

' Stratified Cox model (year of diagnosis: < 1990, 1990-1994, 1995-1999, 2000-2004, $\geq 2005$ ). Adjustment for age at diagnosis, stage of disease at diagnosis (localized, regional, distant), smoking (never, former, or current), physical activity level (sedentary, moderately active, or active), education ( $\leq 9,10-12$, or $\geq 13$ years), and initial BMI (continuous)
} 
microsatellite stable tumors, but not microsatellite instable tumors [31, 32].

We found that weight gain before diagnosis of CRC was related to poorer survival in women, but not in men. Only one study has previously evaluated prediagnostic weight change in relation to survival after CRC [17]. In this study, weight gain since age 20 years was not associated with poorer survival in either men or women. Weight gain in adulthood is mainly an accumulation of fat mass. The distribution of the accumulated fat may influence CRC survival, since various fat depots have different metabolic characteristics [33]. We speculate that weight gain may be more strongly related to harmful fat distribution in women than in men. Also, the timing of weight gain could be important. Possibly, weight gain during menopause is especially harmful. Menopause is associated with an increase in visceral adipose tissue [34], which is particularly related to metabolic disturbances [33]. Many of the women in our study sample likely became postmenopausal between weight measurements; median age at the last weight measurement was 51.7 years for women.

Excess body weight may be linked to increased cancer risk through changes in steroid hormones, insulin, insulin-like growth factors, leptin and adiponectin, or pro-inflammatory cytokines [35]. It is possible that such changes also influence prognosis and survival of cancer, but the biological role of excess body weight on cancer survival is under debate. Also, there may have been differences between normal weight and obese cases in terms comorbidities, receipt of optimal treatment and complications as a result of treatment. Whether this could explain the associations between obesity and mortality among men with proximal colon cancer and women with rectal cancer could not be explored in our study since we did not have information on treatment.

It is of course possible that excess body weight does not influence survival. Weight gain was associated with survival across CRC subsites in women, but we did not observe strong or consistent associations in men. The significant associations we observed may have been due to chance. We performed a large number of statistical tests and would expect to find significant associations even if BMI and weight change are not related to CRC survival. However, it is also likely that the causal effect of obesity and weight change may have been underestimated in our study due to collider-stratification bias [36]. The study population was selected based on occurrence of an event, CRC. Suppose CRC is caused by both obesity and an uncontrolled risk factor. Then CRC is a collider, and conditioning on CRC may result in bias if the uncontrolled risk factor is also a cause of death [36]. The prevalence of the risk factor may be inversely associated with obesity among CRC cases, even when obesity and the risk factor are unrelated in the general population. As a consequence, the association between obesity and risk of death among CRC cases will be biased towards the null or even reversed [37]. Even though we controlled for several important risk factors for CRC and death in our analyses, residual collider-stratification bias cannot be ruled out. However, it is possible that the magnitude of the bias differs with sex or CRC subsite. Future studies should attempt to minimize collider-stratification-bias and must include detailed information on a large number of common causes of CRC and death.

Our study was based on CRC cases from a large cohort study with a very high attendance rate $(80 \%)$. Through linkage with the Cancer Registry of Norway we have identified all cases within the cohort. Because of the prospective design, inclusion of cases did not depend upon duration of survival. Thus, we consider selection bias to be negligible in our study. We cannot exclude the possibility of reverse causation in our study, but given the high median length of time between measurement and diagnosis, weight at the time of measurement is unlikely to have been influenced by pre-existing disease for the majority of the cases. Consequently, reverse causation is presumably not a concern in our study. Another important strength is the accuracy of the exposures. Weight and height were measured by trained nurses following a strict protocol. Furthermore, information on weight was collected up to three times, thus we could study the effect of prediagnostic weight change on CRC survival. We could also examine sex differences, as our study included both men and women.

One limitation of our study is the long time between exposure measurement and diagnosis. Thus, changes in BMI over time may have occurred. However, measurements of BMI made earlier in life have been found to be strongly related to measurements later in life [38, 39]. Moreover, additional adjustment for time between measurement and diagnosis did not change our results. If fat distribution is important in relation to survival after CRC, we may have underestimated the effect of excess body weight, because BMI does not capture fat distribution. We could not explore whether measures of abdominal adiposity like waist circumference or waist-to-hip ratio are more important prognostic factors than BMI, since we did not have information on anthropometry beside BMI. Another limitation is that we could not assess the effect of treatment, a possible confounder, since we did not have information on type of treatment the cases received. Finally, we did not have detailed information on the participants' diet and could therefore not adjust for important risk factors for CRC like intake of red meat and alcoholic drinks. 


\section{Conclusions}

In contrast with what is known about excess body weight and risk of $\mathrm{CRC}$, we found little evidence of poorer survival among men who were obese or gained weight prior to diagnosis of CRC in this study. However, pre-diagnostic weight gain was related to poorer survival after CRC in women. Thus, our study supports that having maintained a healthy weight throughout adulthood may be beneficial for CRC survival, at least for women. The reason for the lack of observed effect in men in our study is not clear. Potential sex differences must be further investigated. Future studies should include detailed information on treatment and a large number of common causes of CRC and death.

\section{Additional files}

Additional file 1: Figure S1. Flow chart illustrating number of cases in each colorectal cancer subsite for the BMI study sample. (PDF 38 kb)

Additional file 2: Figure S2. Flow chart illustrating number of cases in each colorectal cancer subsite for the weight change study sample. (PDF 36 kb)

Additional file 3: Table S1. Hazard ratios and 95\% confidence intervals for all-cause mortality by BMI. (PDF $101 \mathrm{~kb}$ )

Additional file 4: Table S2 Hazard ratios and 95\% confidence intervals for all-cause mortality by weight change. (PDF 104 kb)

\section{Abbreviations}

$\mathrm{BMI}$, body mass index; $\mathrm{Cl}$, confidence interval; $\mathrm{CRC}$, colorectal cancer; $\mathrm{HR}$, hazard ratio; ICD, International Classification of Diseases

\section{Acknowledgement}

None.

\section{Funding}

The study did not receive any funding.

\section{Availability of data and materials}

The data material consists of sensitive information on an individual level. Due to protection of privacy and restrictions from the Norwegian Data Inspectorate and the Regional Committee for Medical and Health Research Ethics the data are not publicly available.

\section{Authors' contributions}

IL, RS, and MBV conceived of the study. IL performed the statistical analyses and drafted the manuscript. IKL contributed to interpretation of the data and helped draft the manuscript. RS and MBV contributed to the statistical analyses, interpretation of the data, and revised the manuscript critically for important intellectual content. IT contributed to interpretation of the data and revised the manuscript critically for important intellectual content. All authors read and approved the final manuscript.

\section{Competing interests}

The authors declare that they have no competing interests.

\section{Consent for publication}

Not applicable.

\section{Ethics approval and consent to participate}

The present study was approved by the Norwegian Data Inspectorate and the Regional Committee for Medical and Health Research Ethics, Southeast Norway. Informed consent was implied by participation. The Regional Committee for Medical Health Research Ethics approved that the study was carried out without new consent from the participants.

\section{Author details}

${ }^{1}$ Oslo Centre for Biostatistics and Epidemiology, Institute of Basic Medical Sciences, University of Oslo, Oslo, Norway. ㄹepartment of Vaccines, Norwegian Institute of Public Health, Oslo, Norway. ${ }^{3}$ Department of Registration, Cancer Registry of Norway, Oslo, Norway. ${ }^{4}$ Department of Pharmaco-epidemiology, Norwegian Institute of Public Health, Oslo, Norway. ${ }^{5}$ Department of Community Medicine, University of Troms $\varnothing$, Troms $\varnothing$, Norway. ${ }^{6}$ Department of Oncology, Oslo University Hospital, Oslo, Norway.

${ }^{7}$ Department of Nutrition, Institute of Basic Medical Sciences, University of Oslo, Oslo, Norway.

Received: 12 January 2016 Accepted: 28 June 2016

Published online: 07 July 2016

\section{References}

1. World Cancer Research Fund/American Institute for Cancer Research. Systematic literature review. Continuous update project report. The association between food, nutrition and physical activity and the risk of colorectal cancer. 2010.

2. Robsahm TE, Aagnes B, Hjartåker A, Langseth H, Bray FI, Larsen IK. Body mass index, physical activity, and colorectal cancer by anatomical subsites: a systematic review and meta-analysis of cohort studies. Eur J Cancer Prev. 2013;22:492-505.

3. Hursting SD, Berger NA. Energy balance, host-related factors, and cancer progression. J Clin Oncol. 2010;28:4058-65.

4. Parekh N, Chandran U, Bandera EV. Obesity in cancer survival. Annu Rev Nutr. 2012;32:311-42.

5. Dignam JJ, Polite BN, Yothers G, Raich P, Colangelo L, O'Connell MJ, et al. Body mass index and outcomes in patients who receive adjuvant chemotherapy for colon cancer. J Natl Cancer Inst. 2006;98:1647-54

6. Hines RB, Shanmugam C, Waterbor JW, McGwin Jr G, Funkhouser E, Coffey CS, et al. Effect of comorbidity and body mass index on the survival of African-American and Caucasian patients with colon cancer. Cancer. 2009;115:5798-806.

7. Sinicrope FA, Foster NR, Sargent DJ, O'Connell MJ, Rankin C. Obesity is an independent prognostic variable in colon cancer survivors. Clin Cancer Res. 2010;16:1884-93.

8. Meyerhardt JA, Tepper JE, Niedzwiecki D, Hollis DR, McCollum AD, Brady D, et al. Impact of body mass index on outcomes and treatment-related toxicity in patients with stage II and III rectal cancer: findings from Intergroup Trial 0114. J Clin Oncol. 2004;22:648-57.

9. Ballian N, Yamane B, Leverson G, Harms B, Heise CP, Foley EF, et al. Body mass index does not affect postoperative morbidity and oncologic outcomes of total mesorectal excision for rectal adenocarcinoma. Ann Surg Oncol. 2010;17:1606-13.

10. Adelstein BA, Macaskill P, Chan SF, Katelaris PH, Irwig L. Most bowel cancer symptoms do not indicate colorectal cancer and polyps: a systematic review. BMC Gastroenterol. 2011:11:65.

11. Lee J, Meyerhardt JA, Giovannucci E, Jeon JY. Association between body mass index and prognosis of colorectal cancer: a meta-analysis of prospective cohort studies. PLoS One. 2015;10:e0120706.

12. Campbell PT, Newton CC, Dehal AN, Jacobs EJ, Patel AV, Gapstur SM. Impact of body mass index on survival after colorectal cancer diagnosis: The Cancer Prevention Study-|| Nutrition Cohort. J Clin Oncol. 2012;30:42-52.

13. Boyle T, Fritschi L, Platell C, Heyworth J. Lifestyle factors associated with survival after colorectal cancer diagnosis. Br J Cancer. 2013;109:814-22.

14. Fedirko V, Romieu I, Aleksandrova K, Pischon T, Trichopoulos D, Peeters PH, et al. Pre-diagnostic anthropometry and survival after colorectal cancer diagnosis in Western European populations. Int J Cancer. 2014;135:1949-60.

15. Reichle K, Peter RS, Concin H, Nagel G. Associations of pre-diagnostic body mass index with overall and cancer-specific mortality in a large Austrian cohort. Cancer Causes Control. 2015;26:1643-52

16. Maskarinec G, Harmon BE, Little MA, Ollberding NJ, Kolonel LN, Henderson $\mathrm{BE}$, et al. Excess body weight and colorectal cancer survival: the multiethnic cohort. Cancer Causes Control. 2015;26:1709-18.

17. Campbell PT, Newton CC, Newcomb PA, Phipps Al, Ahnen DJ, Baron JA, et al. Association between body mass index and mortality for colorectal cancer survivors: overall and by tumor molecular phenotype. Cancer Epidemiol Biomarkers Prev. 2015;24:1229-38. 
18. Haydon AM, Maclnnis RJ, English DR, Giles GG. Effect of physical activity and body size on survival after diagnosis with colorectal cancer. Gut. 2006;55:62-7.

19. Doria-Rose VP, Newcomb PA, Morimoto LM, Hampton JM, Trentham-Dietz A. Body mass index and the risk of death following the diagnosis of colorectal cancer in postmenopausal women (United States). Cancer Causes Control. 2006;17:63-70.

20. Prizment AE, Flood A, Anderson KE, Folsom AR. Survival of women with colon cancer in relation to precancer anthropometric characteristics: the lowa Women's Health Study. Cancer Epidemiol Biomarkers Prev. 2010;19:2229-37.

21. Pelser C, Arem H, Pfeiffer RM, Elena JW, Alfano CM, Hollenbeck AR, et al. Prediagnostic lifestyle factors and survival after colon and rectal cancer diagnosis in the National Institutes of Health (NIH)-AARP Diet and Health Study. Cancer. 2014;120(10):1540-7.

22. Keum N, Greenwood DC, Lee DH, Kim R, Aune D, Ju W, et al. Adult weight gain and adiposity-related cancers: a dose-response meta-analysis of prospective observational studies. J Natl Cancer Inst. 2015;107.

23. Laake I, Thune I, Selmer R, Tretli S, Slattery ML, Veierød MB. A prospective study of body mass index, weight change, and risk of cancer in the proximal and distal colon. Cancer Epidemiol Biomarkers Prev. 2010:19:1511-22.

24. Bjartveit K, Foss OP, Gjervig T, Lund-Larsen PG. The cardio vascular disease study in Norwegian counties. Background and organization. Acta Med Scand Suppl. 1979;634:1-70.

25. Hsieh FY, Lavori PW. Sample-size calculations for the Cox proportional hazards regression model with nonbinary covariates. Control Clin Trials. 2000;21:552-60.

26. World Health Organization. Obesity: Preventing and managing the global epidemic. Report No 894. Geneva: WHO; 2000

27. Park SM, Lim MK, Shin SA, Yun YH. Impact of prediagnosis smoking, alcohol, obesity, and insulin resistance on survival in male cancer patients: National Health Insurance Corporation Study. J Clin Oncol. 2006;24:5017-24.

28. Kuiper JG, Phipps Al, Neuhouser ML, Chlebowski RT, Thomson CA, Irwin ML, et al. Recreational physical activity, body mass index, and survival in women with colorectal cancer. Cancer Causes Control. 2012;23:1939-48.

29. Slattery ML, French TK, Egger MJ, Lyon JL. Diet and survival of patients with colon cancer in Utah: Is there an association. Int J Epidemiol. 1989;18:792-7.

30. Guastadisegni C, Colafranceschi M, Ottini L, Dogliotti E. Microsatellite instability as a marker of prognosis and response to therapy: A metaanalysis of colorectal cancer survival data. Eur J Cancer. 2010;46:2788-98.

31. Campbell PT, Jacobs ET, Ulrich CM, Figueiredo JC, Poynter JN, McLaughlin $J \mathrm{R}$, et al. Case-control study of overweight, obesity, and colorectal cancer risk, overall and by tumor microsatellite instability status. J Natl Cancer Inst. 2010;102:391-400

32. Hughes LA, Williamson EJ, Van EM, Jenkins MA, Giles GG, Hopper JL, et al. Body size and risk for colorectal cancers showing BRAF mutations or microsatellite instability: a pooled analysis. Int J Epidemiol. 2012;41:1060-72.

33. Jensen MD. Role of body fat distribution and the metabolic complications of obesity. J Clin Endocrinol Metab. 2008:93:S57-63.

34. Lovejoy JC, Champagne CM, De JL, Xie H, Smith SR. Increased visceral fat and decreased energy expenditure during the menopausal transition. Int J Obes (Lond). 2008;32:949-58.

35. Roberts DL, Dive C, Renehan AG. Biological mechanisms linking obesity and cancer risk: New perspectives. Annu Rev Med. 2010;61:301-16.

36. Cole SR, Platt RW, Schisterman EF, Chu H, Westreich D, Richardson D, et al. Illustrating bias due to conditioning on a collider. Int J Epidemiol. 2010;39:417-20.

37. Smits $L$, van Kuijk SM, Leffers P, Peeters LL, Prins MH, Sep SJ. Index event bias-a numerical example. J Clin Epidemiol. 2013;66:192-6.

38. Wilsgaard T, Jacobsen BK, Schirmer H, Thune I, Løchen ML, Niølstad I, et al. Tracking of cardiovascular risk factors: the Tromsø study, 1979-1995. Am J Epidemiol. 2001;154:418-26.

39. Ulmer H, Kelleher C, Diem G, Concin H. Long-term tracking of cardiovascular risk factors among men and women in a large population-based health system: the Vorarlberg Health Monitoring \& Promotion Programme. Eur Heart J. 2003;24:1004-13

\section{Submit your next manuscript to BioMed Central and we will help you at every step:}

- We accept pre-submission inquiries

- Our selector tool helps you to find the most relevant journal

- We provide round the clock customer support

- Convenient online submission

- Thorough peer review

- Inclusion in PubMed and all major indexing services

- Maximum visibility for your research

Submit your manuscript at www.biomedcentral.com/submit

C) Biomed Central 